\title{
A whole family-based physical activity promotion intervention: findings from the families reporting every step to health (FRESH) pilot randomised controlled trial
}

\author{
Justin M. Guagliano ${ }^{1 *}$ D , Sofie M. Armitage ${ }^{1}$, Helen Elizabeth Brown ${ }^{1}$, Emma Coombes ${ }^{2}$, Francesco Fusco ${ }^{3}$,
} Claire Hughes $^{4}$, Andrew P. Jones ${ }^{2}$, Katie L. Morton ${ }^{1}$ and Esther M. F. van Sluijs ${ }^{1}$

\begin{abstract}
Introduction: This study assessed the feasibility and acceptability of FRESH (Families Reporting Every Step to Health), a theory-based child-led family physical activity (PA) intervention delivered online. We also assessed the preliminary effectiveness of the intervention on outcomes of interest and whether pre-specified criteria were met to progress to a full-scale definitive trial.

Methods: In a three-armed randomised pilot trial, 41 families (with a 7-11-year-old index child) were allocated to a: 'family' (FAM), 'pedometer-only' (PED), or a no-treatment control (CON) arm. The FAM arm received access to the FRESH website, allowing participants to select step challenges to 'travel' to target cities around the world, log their steps, and track progress as families virtually globetrot. FAM and PED arms also received family sets of pedometers. All family members could participate in the evaluation. Physical (e.g., fitness, blood pressure), psychosocial (e.g., social support), behavioural (e.g., objectively-measured PA), and economic (e.g., expenditure for PA) data were collected at baseline, 8- and 52-weeks.

Results: At 8- and 52-weeks, 98 and 88\% of families were retained, respectively. Most children liked participating in the study (> 90\%) and thought it was fun (> 80\%). Compared to the PED (45\%) and CON (39\%) arms, a higher percentage of children in the FAM (81\%) arm reported doing more activities with their family. Adults agreed that FRESH encouraged their family do more PA and made their family more aware of the amount of PA they do. No notable between-group differences were found for childrens' minutes in moderate-to-vigorous PA. Sizeable changes of $9.4(95 \% \mathrm{Cl}$ : $0.4,18.4)$ and 15.3 (95\%Cl: 6.0, 24.5) minutes in moderate-to-vigorous PA was found for adults in the FAM group compared to those in the PED or CON groups, respectively. No other notable differences were found.

Conclusion: This study demonstrates feasibility and acceptability of the FRESH intervention. All progression criteria were at least partially satisfied. However, we failed to recruit the target sample size and did not find a signal of effectiveness on PA particularly long-term or in children. Further refinements are required to progress to a full-scale trial.
\end{abstract}

Trial registration: This study was prospectively registered (ISRCTN12789422) on 16/03/2016.

Keywords: Youth, Parent, Mothers, Fathers, Mums, Dads, Co-participation, Co-physical activity

\footnotetext{
* Correspondence: Justin.Guagliano@mrc-epid.cam.ac.uk

${ }^{1}$ MRC Epidemiology Unit and Centre for Diet and Activity Research, University of Cambridge, Cambridge, UK

Full list of author information is available at the end of the article
} 


\section{Introduction}

The direct healthcare costs of physical inactivity in the United Kingdom (UK) is among the highest in Europe and is estimated to be INT\$1.5 billion [1]. Approximately one-third of adults in the UK are insufficiently physically active, falling short of achieving the national recommendation of at least $150 \mathrm{~min}$ of moderate- or 75 min of vigorous-intensity physical activity weekly [2, 3]. Adults with school-aged children are particularly at risk for physical inactivity $[4,5]$, and a recent review showed that young adults exhibited greater declines in physical activity over the transition to parenthood compared to those without dependent children [6].

Half of UK children fail to meet the national recommendation of $60 \mathrm{~min}$ of daily moderate-to-vigorous intensity physical activity (MVPA) [7]. Observational data also reveal that children are less active after school and on weekends than during school time, and that activity levels decline most steeply outside of school [8-10]. Targeting children and adults as a family therefore appears to be a promising avenue for promoting physical activity $[11,12]$.

Previous research suggests that involving family members is critical for sustained behaviour change [13-15] and home-based family physical activity interventions are potentially more effective than those requiring the family to travel to community or other intervention locations [16, 17]. Many studies, however, centre around promoting child physical activity instead of considering the family as a unit that may work together to change behaviour [18]. Our recent feasibility study [19] evaluated an intervention that specifically targeted whole family engagement. The findings showed that it was feasible to deliver and evaluate a family-targeted physical activity promotion intervention with high acceptability from participating families.

Building upon this work, here we present the findings from the Families Reporting Every Step to Health (FRES $\mathrm{H})$ pilot trial. The primary aim of this pilot trial was to assess the feasibility and acceptability of the revised recruitment strategy, intervention, and outcome evaluation (i.e., after feasibility testing [19]). Secondary aims were: (1) to explore the preliminary effectiveness of the intervention on potential outcomes of interest and; (2) to assess whether pre-specified criteria were sufficiently met to warrant progression to a full-scale definitive trial.

\section{Methods}

A detailed description of the study protocol has been published elsewhere [20]; a brief summary of the methods is provided below. We received ethical approval from the Ethics Committee for the School of the Humanities and Social Sciences at the University of Cambridge (ID number: 17/113) and this study was prospectively registered (ISRCTN12789422).

\section{Study overview}

This pilot trial was a three-armed, parallel-group, randomised controlled pilot trial using a 1:1:1 allocation ratio and included follow-up assessments at 8- and 52-weeks postbaseline. After baseline assessments, families were randomly allocated to one of the three study arms: (1) family arm, (2) pedometer-only arm, or (3) no-intervention control arm. Families were recruited from the counties of Norfolk and Suffolk, UK.

Recruitment difficulties led to an 8-week extension of the originally planned 16-week period. At minimum, families with at least one child in school Years 3-6 (aged 7-11 years, hereafter referred to as the index child) were eligible to participate if at least one adult responsible for the index child and living in the main household (hereafter referred to as the index parent) provided consent. However, we ideally sought to recruit whole families, that is, all adults and children living in the main household with the index child. If requested, we also enabled the inclusion of parents or siblings that lived outside the main household or extended family members (e.g., grandparents) living inside or outside the index child's main household. All participants were required to be able to perform light-intensity physical activity, have access to the Internet, and have sufficient understanding of the English language to provide informed consent. For this study, we permitted family members to take part in the intervention irrespective of their participation in the accompanying evaluation and vice versa.

We aimed to recruit 60 families using a multi-faceted recruitment strategy that was informed by our prior work $[21,22]$. This approach targeted adults and children, included a wide range of physical settings (such as schools, employers, community settings including community centres, shopping centres, GP surgeries), used electronic media (e.g., social media, television news). It was also based on direct (e.g., face-to-face recruitment during school pick up) and indirect recruitment strategies (e.g., posting recruitment material on parent groups on social media platforms). Following dissemination of recruitment materials, families were encouraged to express interest in participating to the study team, who conducted a screening assessment and scheduled a baseline appointment with eligible families. Prior to baseline assessments, written informed consent was obtained for all participating adults, alongside written parental consent and child assent for each participating child. After baseline assessments, families were randomised in blocks of six and stratified by county (i.e., Norfolk or Suffolk) by an independent statistician using a computer-generated algorithm.

\section{Intervention protocol \\ Family arm (FAM)}

The development, feasibility, acceptability, and refinements made to the intervention prior to the current pilot 
trial have been previously described $[19,20]$, including a detailed description of the FRESH intervention as implemented in the pilot [20]. In summary, families in the FAM arm received a theory-based intervention that was delivered online and aimed at increasing physical activity for the whole family [23-25]. Intervention participation started with a 1-h kick-off meeting in which a member of the research team introduced families to the intervention website, distributed pedometers to all family members, and prompted the first of weekly 'family time' meetings. The index child or children (if multiple) were designated the role of team captain(s) and they led weekly 'family time' meetings. During these meetings, families completed family action planners and accessed the FRESH website which enabled them to choose weekly step challenges. Family action planners prompted families to plan weekly family physical activities to assist in meeting their step challenge for a given week. It was intended that families would plan activities they would do together as a family; however, participants had the flexibility to also set individual level goals. The action planners also prompt families to monitor weekly step counts, discuss any potential upcoming barriers for physical activity and strategies to overcome them. Index children will be allocated as their family's 'team captain' leading in challenge selection and uploading steps on the FRESH website. Families retained their pedometers and were permitted to use the website for as long as they liked, with continuing support.

\section{Pedometer-only arm (PED)}

Following baseline, families allocated to the PED arm were mailed pedometers for all family members and generic family physical activity promotion information produced by Walk4Life, a sub-brand of Change4Life (www.nhs.uk/ change4life). Example information provided included tips to get walking daily and games that can be played while walking. Like FAM families, they continued to receive generic information fortnightly on four occasions.

\section{Control arm (CON)}

$\mathrm{CON}$ families were asked to carry on as normal and did not receive access to the intervention website, pedometers, or any generic information.

\section{Outcome evaluation measures}

All consenting family members were assessed at baseline, 8 , and 52 weeks post-baseline and data were collected in the family home by two trained research staff.

\section{Accelerometer and GPS assessment}

Participants were asked to simultaneously wear an ActiGraph GT3X+ tri-axial accelerometer (ActiGraph LLC; Pensacola, Florida) and QStarz Travel Recorder BT1000X global positioning system (GPS) monitor (QStarz; Taipei,
Taiwan) on each hip during waking hours for 7 consecutive days. After the 7 days of wear, participants either posted the devices back to the research team using prepaid envelopes or the research team picked up the devices at an agreed time.

The accelerometer was initialised to record step counts and acceleration using a sampling frequency of $50 \mathrm{~Hz}$. Data from the device were then downloaded and interpolated to a $10 \mathrm{~s}$ epoch using the ActiLife software. A valid week for the accelerometery was defined as a minimum of $480 \mathrm{~min} /$ day from 3 days (including 1 weekend day) over the 7-day measurement period. Non-wear was defined as $\geq 90$ mins of consecutive zeros [26]. The cut points of Evenson et al. [27] and Troiano et al. [28] were used to estimate physical activity for children and adults, respectively.

The GPS device recorded participants' locations at a $10 \mathrm{~s}$ interval with an accuracy of approximately $3 \mathrm{~m}$. Data from the GPS devices were downloaded and entered into the ArcGIS v10.3 (ESRI Inc., California, USA) Geographical Information System, and then longitude and latitude values were converted to easting and northing values respectively according to the British National Grid coordinate reference system [29].

The accelerometer and GPS data were then integrated based on their date and time-stamps using bespoke software written in Java. From the integrated accelerometer and GPS data, individual measures of time spent with and without other family members present were computed. This was undertaken using a script written in STATA v16 (StataCorp LLC, Texas, USA) that calculated the straightline distance between each participant and every member of their family for all $10 \mathrm{~s}$ intervals, based on each participant's easting and northing locations. To identify physical activity undertaken together, a distance of $\leq 50 \mathrm{~m}$ was taken as being indicative of the same location of members of the family during any given $10 \mathrm{~s}$ interval. This distance was selected because it is approximately equivalent to a ball court (e.g. tennis, basketball) or a large residential garden [30].

\section{Physical health outcomes}

Aerobic fitness (via predicted $\mathrm{VO}_{2}$ max) was measured using an 8-min submaximal step test (with 2-min rest) on all participants $\geq 7$ years [31]. Height and weight were measured with a portable stadiometer and digital scale, respectively. Waist circumference was measured twice, using a non-elastic tape measure (third measure taken if the first two differed by $\geq 3 \mathrm{~cm}$ ). Body mass index was calculated, and converted into age- and sex-specific percentiles using standard growth charts for children [32].

\section{Behavioural and psychosocial measures}

Behavioural and psychosocial measures were measured via questionnaires for participants $\geq 4$ years. Measures included: screen-time use [33-36]; quality of life [37-40]; 
family co-participation in physical activity [36]; physical activity awareness [41, 42]; family social norms for physical activity [43, 44]; family support [43]; motivation for physical activity [45, 46]; and children's perceived autonomy, competence, and relatedness [46].

\section{Family functioning}

The Fictional Family Holiday Paradigm was used to assess family functioning via family relationships [47] and connectedness [48]. In this observational paradigm, each family was asked to spend 10 min planning and discussing a fictional week-long holiday itinerary with unlimited budget. The video-recorded activity was then transcribed and coded by trained research assistants per time point for: 'power sharing' (i.e., taking turns speaking); positive talk (e.g., expressions of amity, elicitation of family members' viewpoints, agreement, compromise) [48], and discussions that revolve around physical activity.

\section{Family out-of-pocket expenditure for physical activity}

Physical activity related expenditure for each family member was collected via questionnaire. The questionnaire comprised two questions about expenditure related to membership fees and subscriptions (e.g., for sports clubs, fitness centres) and sports equipment (e.g., sportswear, gadgets) and was completed by the same adult at each time point for their whole family.

\section{Feasibility and acceptability assessment}

A mixed-methods process evaluation was conducted at 8 weeks post-baseline. Adults responded to open-ended and Likert-scale questions (4-point; $1=$ strongly disagree, $4=$ strongly agree) and children responded to dichotomous 'yes/no' questions regarding their overall opinion of FRES $\mathrm{H}$, the intervention components, measurements, and suggestions for improvement. In addition, semi-structured focus groups were conducted with willing families $(n=5$ FAM; $n=4$ PED; $n=1$ CON). This focused on families' experience taking part in the trial, perceived acceptability of individual intervention components, intervention fidelity, challenges/barriers encountered, and suggested improvements, as appropriate based on study arm allocation. All focus groups were transcribed verbatim. We also explored FAM arm families' engagement with the intervention website through Google Analytics (e.g., page views, challenges accepted/completed) and assessed aspects of the recruitment process (e.g., recruitment duration, resources used, comparisons of recruitment strategies). Lastly, intervention costs were also calculated.

\section{Progression criteria assessment}

Table 1 outlines pre-specified criteria used to inform progression to a definitive trial. Where applicable, quantitative and qualitative findings were taken into account to assess whether a criterion was met.

\section{Data analysis \\ Quantitative data}

Statistical analyses of the primary and selected secondary outcomes were conducted using analysis of covariance (adjusting for baseline values) in Stata (version 15; StataCorp. TX: StataCorp LP), stratified by age group (adults vs children). Participants with missing values at baseline were included in the analysis using the missing indicator method [49]. An estimate of effect and 95\% confidence interval were calculated for primary and selected secondary outcomes; no $p$-values were calculated. We stratified analyses by index of multiple deprivation (IMD) score (high/low IMD determined by median split) and sex to explore signals of subgroup effects in all outcomes.

To inform one of the progression criteria, post-hoc sample size calculations were calculated to provide $80 \%$ power to detect a difference of 10 mins in MVPA in index children $(p<0.05)$, using a standard deviation of 16.3 mins of MVPA and a pre-post correlation of 0.63 (values obtained from 52-week follow-up).

\section{Economic analyses}

The intervention costs were calculated by using a microcosting approach [50]. Table 2 reports the resources used per family, and their monetary value, alongside the subsequent cost per item. All families were assumed to incur the same intervention cost, except from the pedometers, which was based on the number of participants per family. The reported family physical activity expenditure was summed per each family and the mean costs per family was calculated at each time point.

We conducted a comparative analysis based on the complete-cases dataset at 52 weeks. A linear regression was used to estimate the between-groups differences in mean costs per family, accounting for the cost at baseline (incurred during the 3 months prior to baseline) [51]. The $95 \%$ CIs were constructed by resampling the dataset 5000 times performing a non-parametric bootstrap with replacement.

\section{Qualitative data}

A content analysis was conducted using existing guidelines [52] to explore the feasibility and acceptability of the revised FRESH intervention, outcome evaluation, and suggestions for further intervention optimisation via family focus groups.

\section{Results}

\section{Recruitment and retention}

Table 3 provides a summary of recruitment sources used in this study and Fig. 1 shows the recruitment flow. Expressions of interest occurred at a rate of 4-5 families/ 
Table 1 Descriptions and assessments of pre-specified criteria used to inform progression to a definitive trial

\begin{tabular}{|c|c|c|}
\hline Description & $\begin{array}{l}\text { Criterion } \\
\text { met? }\end{array}$ & Assessment \\
\hline $\begin{array}{l}\text { 1. }>75 \% \text { of families upload steps at least } 6 \text { times in the first } 3 \\
\text { months of pilot study. }\end{array}$ & Yes & $\begin{array}{l}\text { - } 86 \% \text { of families uploaded steps }>6 \text { times in first } 3 \text { months } \\
\text { (mean } \pm \mathrm{SD}=11 \pm 4 \text { uploads). }\end{array}$ \\
\hline $\begin{array}{l}\text { 2. Demonstrable feasibility of recruiting } 20 \text { families/month } \\
\text { (accounting for increased staffing in future definitive trial) and } \\
\text { retaining } 75 \% \text { of index children at } 52 \text {-week follow up. }\end{array}$ & Partially & $\begin{array}{l}\text { - The average recruitment rate was approximately } \sim 7 \pm 5 \text { families/ } \\
\text { month (range }=2-15 \text { families/month). } \\
\text { - } 88 \% \text { of index children were retained at } 52 \text {-week follow up. }\end{array}$ \\
\hline $\begin{array}{l}\text { 3. Intervention optimisation feasible (identified adaptations are } \\
\text { practical, affordable, acceptable). }\end{array}$ & Yes & $\begin{array}{l}\text { - Focus groups revealed few suggested changes to the website; } \\
\text { however, some families indicated a preference for the intervention } \\
\text { to be delivered through a mobile phone app rather than a } \\
\text { website. } \\
\text { - Many families suggested receiving wrist-worn pedometers. }\end{array}$ \\
\hline $\begin{array}{l}\text { 4. Evidence to suggest an adequately powered trial would require } \\
\text { a feasible number of participants }(N=250 \text { is considered logistically } \\
\text { feasible and providing sufficient power). }\end{array}$ & Yes & $\begin{array}{l}\text { - Post-hoc sample size calculations were performed and to provide } \\
80 \% \text { power to detect a difference of } 10 \text { mins in MVPA in index } \\
\text { children, } 27 \text { index children/family are needed, using a standard de- } \\
\text { viation of } 16.3 \text { mins of MVPA and a pre-post correlation of } 0.63 \text {. } \\
\text { o With } 3 \text { arms: } 27 \text { index children * } 4 \text { people/family * } 3 \text { arms; } N=81 \\
\text { families ( } \sim 324 \text { total participants) } \\
\text { o With } 2 \text { arms: } 27 \text { index children * } 4 \text { people/family * } 2 \text { arms; } N=54 \\
\text { families ( } 216 \text { total participants) } \\
\text { - Therefore, to conduct an adequately powered trial with a feasible } \\
\text { number of participants it will have to be a } 2 \text {-armed study. }\end{array}$ \\
\hline $\begin{array}{l}\text { 5. Discontinuation of trial arm based on evidence of harm or } \\
\text { limited acceptability/feasibility. }\end{array}$ & Yes & $\begin{array}{l}\text { - There were no reports of harm, however, during the focus groups } \\
\text { some pedometer only-armed families unknowingly indicated that } \\
\text { they would have liked to receive several elements that were deliv- } \\
\text { ered to families in the family-arm (e.g., step challenges). This find- } \\
\text { ing provides some evidence to suggest the pedometer only-arm } \\
\text { could be discontinued in future. }\end{array}$ \\
\hline
\end{tabular}

week over the 24-week recruitment period. Approximately $77 \%$ of families expressing interest were eligible for participation and $48 \%$ of eligible families were enrolled, with an enrolment rate of $\sim 1-2$ families/week.

Of the 41 families enrolled, $73 \%$ included all family members ( $n=30$ families). The remaining families either only included index parent-child dyads $(n=4$ families) or the index parent, index child, and an additional parent and/or children ( $n=7$ families); however, in all cases there were additional adults and/or children living with the index child that chose not to participate in the study. We did not recruit any extended family members or any family members that lived outside the index child's main household. Consent was obtained for 149 participants, averaging $\sim 4$ members/family (range $=2-6$ family members) and included 39 mothers (95\%), 31 fathers (76\%), and 41 siblings (from 32 families with an eligible sibling, $78 \%)$. Eleven siblings were younger than index children ( $<7$ years of age), 15 were in the same age category (711 years) and 15 were older ( $>11$ years). Table 4

Table 2 Intervention cost components and cost per item/family

\begin{tabular}{|c|c|c|c|}
\hline Items & Resource use & Unit cost $(£)$ & Cost/item ( $(£)$ \\
\hline \multicolumn{4}{|l|}{ Family arm } \\
\hline Kick-off meeting & $75 \min ^{+}$ & 0.33 & 25 \\
\hline Accompanying booklet & 12 pages & 0.20 & 2.4 \\
\hline Pedometers & 1 pedometer per study participant & 4.00 & 4 \\
\hline Personalised messages & 118 Minutes $^{++}$ & 0.33 & 39.3 \\
\hline Online and tangible rewards & 5 cards & 0.20 & 1 \\
\hline Total cost & - & - & 71.7 \\
\hline \multicolumn{4}{|l|}{ Pedometer-only arm } \\
\hline Pedometers & 1 pedometer per study participant & 4.00 & 4 \\
\hline Accompanying booklet & 12 pages & 0.20 & 2.4 \\
\hline Total cost & - & - & 6.4 \\
\hline
\end{tabular}

Note. ${ }^{+}$Kick-off meeting duration: 60 min; travelling time: 15 min. ${ }^{++}$The personalised messages were posted for 11 weeks, which required on average 10.72 min per week per family 
Table 3 Recruitment sources

\begin{tabular}{|c|c|c|c|c|c|c|c|c|}
\hline & Schools & Employers & Community $^{a}$ & Traditional media $^{b}$ & Social media $^{c}$ & Referral & Unknown & Total \\
\hline Approached & 87 & 102 & 56 & $\mathrm{~N} / \mathrm{A}$ & 12 & N/A & $\mathrm{N} / \mathrm{A}$ & 257 \\
\hline Agreed & 16 & 10 & 7 & N/A & 5 & N/A & N/A & 38 \\
\hline Families reached & $\sim 1641$ & $\sim 8761$ & $\sim 1740$ & $\sim 2371$ & 24,333 & N/A & N/A & $\sim 38,846$ \\
\hline Expressions of interest & 42 & 11 & 26 & 22 & 1 & 4 & 6 & 112 \\
\hline Eligible & 41 & 9 & 22 & 7 & 1 & 4 & 2 & 86 \\
\hline Families enrolled & 23 & 7 & 4 & 4 & 0 & 3 & 0 & 41 \\
\hline
\end{tabular}

Note. ${ }^{a}$ Included settings such as: parkrun, community centres, swimming pools, Scouts/Cubs/Guides, shopping centres, local community events. ${ }^{\mathrm{b}}$ Included a story highlighting the study on a local television news program. Included parent websites or groups on FaceBook and Twitter

describes the participant characteristics at baseline. Notably, children in the family arm were older compared to children in the other two arms (FAM: $10.1 \pm 2.8 \mathrm{y}$; PED: $8.6 \pm 1.9$; CON $8.9 \pm 2.7 y$ ) and there were fewer girls allocated to the pedometer arm (FAM: 50.0\%; PED: 17.4\%; CON 48.3). Approximately, $92 \%$ of adults reported being married or living as married, $94 \%$ of adults reported their ethnicity as white, and the mean $\pm S D$ age that adults finished full-time education was $20.5 \pm 3.5$ years.

At 8- and 52-weeks assessments, 98 and $88 \%$ of families were retained (family drop out: $n=2$ FAM; $\mathrm{n}=2$ PED; $n=$ $1 \mathrm{CON}$ ), respectively. Participant loss to follow-up at 52 weeks included 9 adults ( $n=4$ FAM; $n=3$ PED; $\mathrm{n}=2$ $\mathrm{CON}$ ) and 11 children ( $n=4$ FAM; $n=3$ PED; $n=4 \mathrm{CON})$.

\section{Intervention feasibility, acceptability, fidelity, and optimisation}

Most children reported that they liked taking part in the study (>90\%) and thought it was fun (>80\%). Compared to the PED (45\%) and CON (39\%) arms, a higher percentage of children in the FAM (81\%) arm reported doing more activities with their family at 8-week follow up. Table 5a shows adults' overall perceptions of FRESH. Scores were generally positive and favoured the FAM over the PED arm. In particular, adults agreed that FRES $\mathrm{H}$ encouraged their family do more physical activity and made their family more aware of the amount of physical activity they do. Focus group findings also related to family physical activity, physical activity awareness, and parental modelling, for example:

"It was really fun, it pushed us to get our steps in and do more activities and sports together, you know. I never really thought about how many steps or exercise I've done to be honest, so since these [step] counters, I just look and go '3,000 [steps] only? I have to do something'. So sometimes they [her 3 sons] come home and they see me... dancing, doing something, or skipping, they say, 'what are you doing, mum?' [laughs] and I say, 'I'm just putting effort in to get my steps' and then they join me, you know. It just made your more aware... I even started walking for small shopping instead of driving just to get my steps up [laughs]... small things, you know, it just made you aware." (Mother of 3, FAM group).

Overall acceptability of the pedometers was fairly high for adults in both the FAM and PED arms (Table 5b). Families in both groups reported that it became habitual to wear the pedometers; one parent stated: "I think it's become quite habitual now, we pick them up first thing in the morning and take them off last thing at night and they [her children] were quite happy to do that, so that was good from a parent point of view." (Mother of 2, FAM group). A greater percentage of PED children selfreported that they liked wearing their pedometer compared to FAM children ( $86 \%$ vs. $62 \%$ ). Also, compared to our previous feasibility study, families' preference to wear wrist-worn pedometers was emphasised more strongly during focus group discussions in this study.

Based on a 4-point Likert scale ( $1=$ strongly disagree, $4=$ strongly), FAM adults found the kick-off meeting useful (mean $\pm \mathrm{SD}=3.6 \pm 1.0$ ) to help them get started, felt they had enough technical support if needed $(3.9 \pm 0.6)$, and found it feasible to schedule 'family time' but not consistently so (see Table 5c). Focus groups revealed that families were rarely using their action planners. One parent described: "we probably didn't fill that [action planner] in as much as we should've... we use that [action planner] more to actually record our steps." (Father of 2, FAM group).

The majority of FAM children found the website easy to use (93\%), wanted to keep using it (81\%), enjoyed being their family's team captain (70\%), and did not find it too difficult to reach their step goals (65\%). Overall, adults' mean scores were generally positive in relation to the intervention website (see Table 5d). In particular, adults strongly agreed that the website was easy to use and found various website elements to be useful (e.g., the step converter). Parents agreed that their child enjoyed receiving rewards and competence reinforcement after each challenge week (mean $\pm \mathrm{SD}=3.5 \pm 1.2$ ), based on a 4-point Likert scale ( $1=$ strongly disagree, $4=$ strongly). When asked in focus groups about suggestions for improvement, 


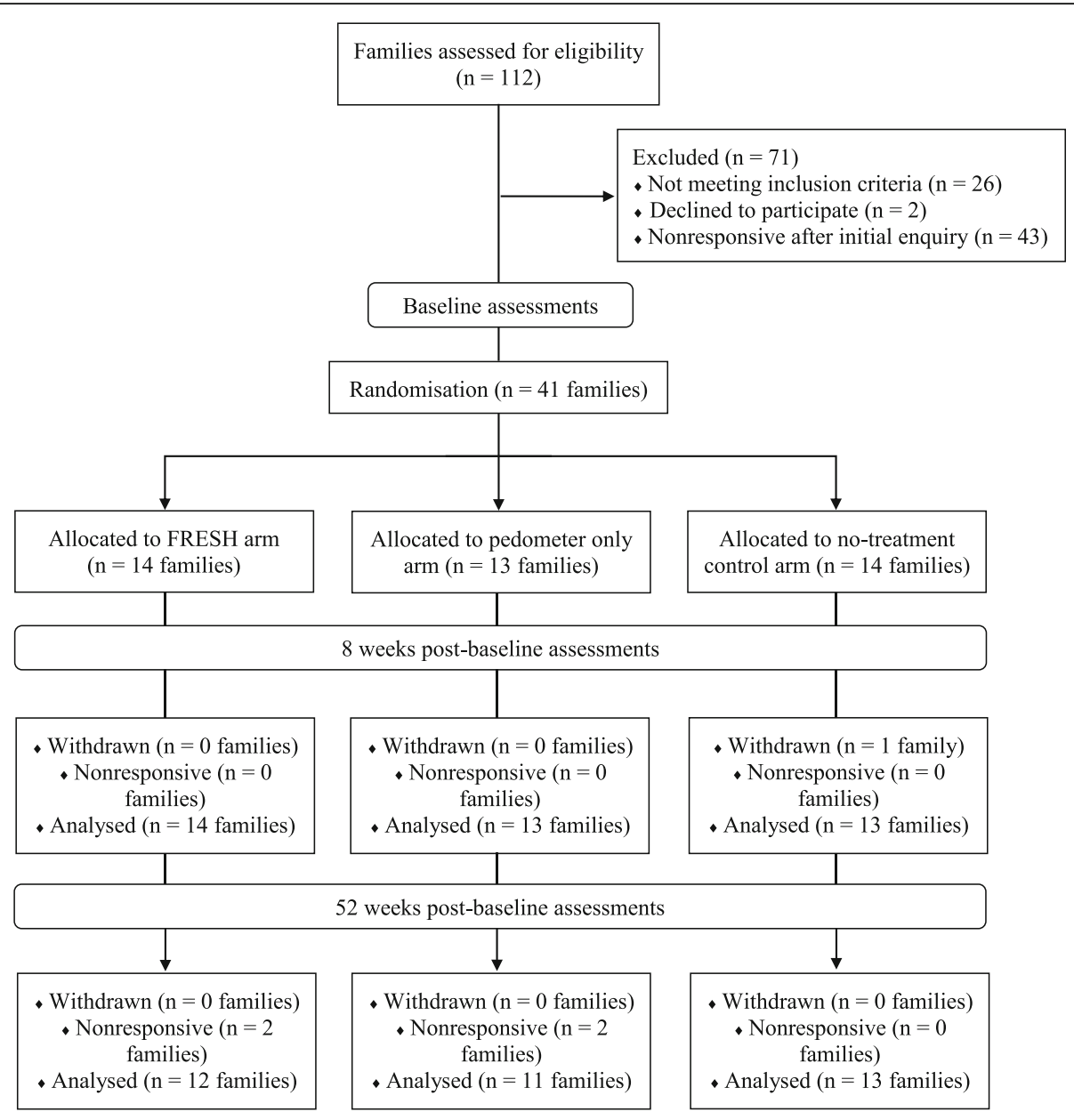

Fig. 1 Participant flow diagram

PED families suggested elements that were delivered to the FAM group, for example:

"I think if you can walk so many steps and it gets you to a place, like a country or something like that.
So maybe there could be mini challenges like you walk to London or walk to Paris, you know, or something. Yeah, something like that would be probably quite good for you guys [referring to her children]. [...] We haven't been around the world,

Table 4 Individual Participant Characteristics at Baseline

\begin{tabular}{|c|c|c|c|c|c|c|c|c|}
\hline & \multicolumn{2}{|l|}{ Overall } & \multicolumn{2}{|l|}{ Family } & \multicolumn{2}{|l|}{ Pedometer } & \multicolumn{2}{|l|}{ Control } \\
\hline & $\begin{array}{l}\text { Adults }(n= \\
67)\end{array}$ & $\begin{array}{l}\text { Children }(n= \\
82)\end{array}$ & $\begin{array}{l}\text { Adults }(n= \\
21)\end{array}$ & $\begin{array}{l}\text { Children }(\mathrm{n}= \\
30)\end{array}$ & $\begin{array}{l}\text { Adults }(n= \\
24)\end{array}$ & $\begin{array}{l}\text { Children }(n= \\
23)\end{array}$ & $\begin{array}{l}\text { Adults }(n= \\
22)\end{array}$ & $\begin{array}{l}\text { Children }(n= \\
29)\end{array}$ \\
\hline Sex (\% female) & 56.7 & 40.2 & 54.2 & 50.0 & 50.3 & 17.4 & 57.1 & 48.3 \\
\hline Age, yr ( \pm SD) & $41.3 \pm 5.8$ & $9.3 \pm 2.6$ & $42.7 \pm 5.3$ & $10.1 \pm 2.8$ & $39.0 \pm 6.2$ & $8.6 \pm 1.9$ & 42.2 & $8.9 \pm 2.7$ \\
\hline Height, cm ( \pm SD) & $171.8 \pm 9.1$ & $136.3 \pm 15.6$ & $172.4 \pm 8.8$ & $140.4 \pm 14.8$ & $172.8 \pm 9.6$ & $135.1 \pm 11.7$ & $170.0 \pm 9.0$ & $132.9 \pm 18.4$ \\
\hline Weight, kg ( \pm SD) & $78.1 \pm 14.2$ & $32.5 \pm 9.6$ & $81.3 \pm 13.8$ & $35.2 \pm 9.1$ & $76.5 \pm 13.0$ & $31.4 \pm 7.8$ & $76.3 \pm 15.7$ & $30.7 \pm 10.9$ \\
\hline $\begin{array}{l}\text { Body mass index, } \mathrm{kg} \cdot \mathrm{m}^{-2} \\
( \pm \mathrm{SD})\end{array}$ & $26.5 \pm 4.6$ & $17.1 \pm 2.4$ & $27.5 \pm 5.0$ & $17.6 \pm 2.4$ & $25.6 \pm 3.4$ & $16.9 \pm 2.3$ & $26.3 \pm 5.3$ & $16.8 \pm 2.5$ \\
\hline $\begin{array}{l}\text { Body mass index } Z \text {-score } \\
( \pm S D)\end{array}$ & $\mathrm{N} / \mathrm{A}$ & $0.1 \pm 1.1$ & $\mathrm{~N} / \mathrm{A}$ & $0.2 \pm 1.1$ & $\mathrm{~N} / \mathrm{A}$ & $0.3 \pm 1.1$ & $\mathrm{~N} / \mathrm{A}$ & $0.0 \pm 1.1$ \\
\hline $\begin{array}{l}\text { Waist circumference, } \mathrm{cm} \\
( \pm \mathrm{SD})\end{array}$ & $89.1 \pm 12.2$ & $61.0 \pm 8.0$ & $93.4 \pm 12.0$ & $62.4 \pm 9.1$ & $86.6 \pm 12.5$ & $62.0 \pm 5.8$ & $86.9 \pm 11.3$ & $59.0 \pm 8.2$ \\
\hline
\end{tabular}


Table 5 Summary Process Evaluation Findings for Adult Participants Assessing the Acceptability of the Families Reporting Every Step to Health (FRESH) intervention

\begin{tabular}{|c|c|c|}
\hline & $\begin{array}{l}\text { Family arm }(n=25 \\
\text { adults) }\end{array}$ & $\begin{array}{l}\text { Pedometer-only arm ( } \mathrm{n}=21 \\
\text { adults) }\end{array}$ \\
\hline \multicolumn{3}{|l|}{ a) The FRESH study... } \\
\hline ...was fun for my family and $\mathrm{I}$. & $3.2 \pm 0.7$ & $3.1 \pm 0.5$ \\
\hline ...encouraged my family and I to do more physical activity. & $3.2 \pm 0.7$ & $2.7 \pm 0.8$ \\
\hline ... has led my family and I to do more physical activity than we did before FRESH. & $3.0 \pm 0.8$ & $2.4 \pm 0.8$ \\
\hline $\begin{array}{l}\text {...has led my family and I to do more activities (other than physical activity) together } \\
\text { than we did before FRESH. }\end{array}$ & $2.6 \pm 0.8$ & $2.2 \pm 0.5$ \\
\hline ...has made my family and I more aware of the amount of physical activity we do. & $3.6 \pm 0.6$ & $3.2 \pm 0.7$ \\
\hline ... is something my family and I would like to continue to be part of. & $3.3 \pm 0.9$ & $3.2 \pm 0.6$ \\
\hline \multicolumn{3}{|l|}{$\begin{array}{l}\text { b) Regarding the step counter we gave out to log your steps, to what extent do } \\
\text { you agree or disagree with the following: }\end{array}$} \\
\hline I didn't mind wearing it. & $3.4 \pm 1.0$ & $3.1 \pm 1.1$ \\
\hline My child/children didn't mind wearing it. & $3.2 \pm 1.0$ & $3.2 \pm 0.9$ \\
\hline It was easy to use. & $3.1 \pm 0.9$ & $3.6 \pm 0.5$ \\
\hline I thought it was reasonably reliable at counting steps. & $2.8 \pm 1.0$ & $3.0 \pm 0.6$ \\
\hline $\begin{array}{l}\text { I used the memory feature to go back and look at the number steps my family } \\
\text { and/or I took. }\end{array}$ & $3.0 \pm 1.1$ & $2.0 \pm 1.1$ \\
\hline \multicolumn{3}{|l|}{ c) Regarding 'family time', to what extent do you agree or disagree with the following: } \\
\hline It was easy to schedule 'family time'. & $3.0 \pm 1.0$ & N/A \\
\hline My family consistently scheduled 'family time'. & $2.4 \pm 1.0$ & N/A \\
\hline My child reminded us about 'family time'. & $3.0 \pm 0.9$ & N/A \\
\hline My child led/initiated 'family time'. & $3.1 \pm 0.8$ & N/A \\
\hline \multicolumn{3}{|l|}{ d) Regarding the FRESH website, to what extent do you agree or disagree with the following: } \\
\hline It was easy to use. & $3.8 \pm 0.7$ & N/A \\
\hline I enjoyed using it. & $3.4 \pm 0.8$ & N/A \\
\hline My child/children enjoyed using it. & $3.4 \pm 0.8$ & N/A \\
\hline I thought the website was appealing. & $3.5 \pm 0.7$ & N/A \\
\hline I liked that there were varying degrees of difficulty with the challenges. & $3.5 \pm 0.8$ & N/A \\
\hline I enjoyed the information about the cities. & $3.5 \pm 0.8$ & N/A \\
\hline My child/children enjoyed the information about the cities. & $3.4 \pm 0.8$ & N/A \\
\hline The step converter was useful (e.g., converting swimming to steps). & $3.6 \pm 0.8$ & N/A \\
\hline The resources page was useful. & $3.5 \pm 1.0$ & N/A \\
\hline I enjoyed the recipes. & $3.6 \pm 1.4$ & N/A \\
\hline My child/children enjoyed the recipes. & $3.6 \pm 1.4$ & N/A \\
\hline Logging our steps was easy. & $3.5 \pm 0.9$ & N/A \\
\hline
\end{tabular}

Note. Participants responded on a 4-point Likert scale for each question ( $1=$ strongly disagree; $4=$ strongly agree)

but we'd like to go around the world. [...] I think that's something you can add to this [study]. (Mother of 2, PED group).

Google Analytics data indicated that 59 users accessed the website ( $\sim 4$ users/family) with a median (interquartile range) of 2 (1-5) sessions/user, viewing about 5 (211) pages/session, for about 7 (3-12) minutes/session. The most common behaviour flow was to log on, access the challenge page (to select a new challenge) and then access the steps page (to add steps to complete their challenge). Families selected an average of 11 challenges and completed 9 of those.

\section{Findings related to feasibility and acceptability of the outcome evaluation}

Data collection took an average of $119.5 \pm 26.4 \mathrm{~min} / \mathrm{fam}-$ ily at baseline and $95.0 \pm 16.7$ and $82.3 \pm 35.8 \mathrm{~min} /$ family at 8 - and 52-week follow up, respectively. Overall, adults disagreed that there were too many measures (mean \pm 
$\mathrm{SD}=1.5 \pm 0.7)$ and that data collection took too long (mean $\pm \mathrm{SD}=1.7 \pm 0.8)$, based on a 4-point Likert scale $(1=$ strongly disagree, $4=$ strongly). Focus group families highlighted the convenience of home-based data collection and, in some cases, it was essential for their participation. One parent indicated: “...it was a lot more convenient you coming to us and you guys being quite flexible in offering us multiple dates and times you could come... if you hadn't come to us, we probably wouldn't have participated." (Father of 1 , FAM group). Also, $>80 \%$ children reported that they 'liked' the measurement sessions. At each time point, > $90 \%$ of eligible adults and children completed all measures, except for the submaximal step test (86\%) and the video-recorded activity assessing family functioning (89\%).

Valid accelerometer wear was $835.6 \pm 76.5$ and $734.9 .4 \pm 62.7 \mathrm{~min}$ for adults and children across time points, respectively. Valid accelerometer data on $\geq 3$ days (including 1 weekend day) was available for $82 \%$ of adults and $77 \%$ of children over the 3 measurement time points. On average across time points, the GPS provided a location for $757.0 \pm 126.3$ and $541.6 \pm 200.3 \mathrm{~min}$ for adults and children across time points, respectively.

\section{Preliminary effectiveness}

Levels of MVPA and sedentary behaviour for children and adults are presented in Table 6, subgroup analyses are in Supplementary Tables 1 and 2 and family co-participation in physical activity is available in Supplementary Table 3. Children and adults were either meeting or close to meeting recommended levels of MVPA at baseline, with the exception of FAM children who accumulated notably less MVPA compared to PED and CON children.

In children, there were no notable between-group differences found for minutes in MVPA, time spent sedentary, or co-participation in physical activity with family members. However, a sizeable change of 9.4 (95\% CI: 0.4, 18.4) and 15.3 (95\% CI: 6.0, 24.5) minutes in MVPA was found for adults in the FAM group compared to those in the PED or CON groups, respectively. Adults in the FAM group also did more activity together compared to the CON and PED groups where there was a change of 11.2 (95\% CI: - 2.9, 25.4) and 15.8 (95\% CI: 0.5, 31.0) mins, respectively, although in both cases, adult activity was not maintained at 52-weeks. No between-group group differences were found for time spent sedentary in adults.

Exploratory subgroup analyses showed a greater decline in MVPA for FAM girls and FAM children from less deprived areas compared to their counterparts. The latter group also showed a greater increase in sedentary behaviour. In contrast, FAM adults, in particular men, showed a greater increase in MVPA at 8-weeks.

Supplementary Tables 4, 5, 6 display the findings for children and adults for all other outcomes. There were no other notable between-group or subgroup differences found for any other outcome measured at 8- or 52weeks for children and adults.

\section{Evaluation of costs}

The proportion of families who bought any sports items was materially unaltered throughout the study. Table 7 reports the costs incurred by the family and the intervention cost. The summation of the costs from randomisation to 52-week follow up showed that FAM arm expenditure was on average $£ 157.92$ (95\% CI: - 154.76, 484.79) more than CON. The majority of this cost difference is accounted for by the cost of the intervention, which is covered by the local authorities. Conversely, CON family expenditure tended to be greater than PED family where an average of $£ 90.50$ (95\% CI: - $£ 301.30,104.45)$ was spent.

\section{Progression criteria findings}

Table 1 shows the findings for each progression criterion, where each was at least partially met.

\section{Discussion}

Our findings showed that it was feasible to deliver and evaluate a family-targeted physical activity promotion intervention with generally high acceptability from participating families. In addition, each of the pre-specified progression criteria were at least partially met (Table 1). However, we only found a favourable indication of effectiveness for adults and not children, that is, a sizeable positive change in MVPA for adults in the FAM group compared to the other groups. The between-group difference found for adults' minutes in MVPA was not maintained at 52-weeks follow-up and we also found no notable between-group differences for any other outcome measured at either time point.

Family recruitment posed a substantial challenge, and this progression criterion was not met (i.e., recruiting 20 families/month). Our average recruitment rate was $\sim 7$ families/month (range $=2-15$ families/month) despite using a multi-faceted recruitment strategy that targeted adults and children, included a wide range of settings, and direct and indirect recruitment strategies. The recruitment of participants into intervention research has been notoriously difficult $[53,54]$. A review of 73 publicly funded trials in the UK (through the National Institute for Health Research) found that only $55 \%$ recruited $100 \%$ of their target sample size within their pre-agreed timescale and nearly $45 \%$ received an extension of some kind [55]. Several studies have reported that the recruitment of families is particularly challenging $[13,56]$ and we have described specific recruitment challenges we have encountered previously [19]. However, the extent to which under-recruitment occurs in family-based research in unclear. A recent systematic review and Delphi survey investigating effective and resource efficient strategies for recruiting families in physical activity, 


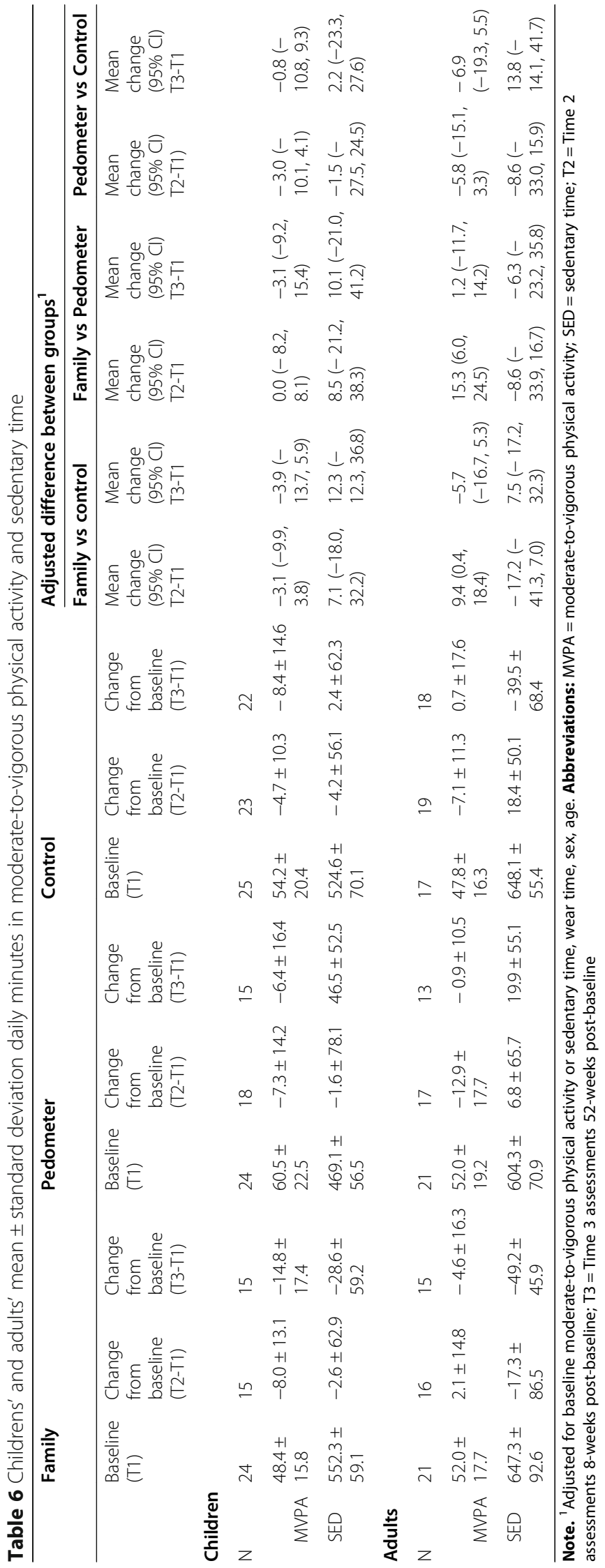


Table 7 Average costs $(95 \% \mathrm{Cl})$ in pound sterling aggregated at family-level

\begin{tabular}{llll}
\hline & Control $(\boldsymbol{n}=\mathbf{1 4})$ & Family $(\mathbf{n}=\mathbf{1 4})$ & Pedometer $(\boldsymbol{n}=\mathbf{1 3})$ \\
\hline T1 & $200.9(131.0,270.8)$ & $195.1(110.2,279.9)$ & $183.1(118.1,248.1)$ \\
Intervention $^{+}$ & $\mathrm{N} / \mathrm{A}$ & $90.0(84.5,95.4)$ & $24.6(19.0,30.1)$ \\
Pedometers & $\mathrm{N} / \mathrm{A}$ & $22.3(16.9,27.7)$ & $22.2(16.6,27.7)$ \\
Other components & $\mathrm{N} / \mathrm{A}$ & $67.7(-)$ & $2.4(-)$ \\
T2 & $115.6(65.3,165.9)$ & $89.8(33.9,145.7)$ & $104.9(39.9,169.9)$ \\
T3 & $322.2(171.4,473.0)$ & $409.8(137.6,681.9)$ & $239.5(112.0,367.0)$ \\
Total cost & $437.8(275.9,599.7)$ & $595.7(307.5,883.9)$ & $347.3(216.3,478.3)$ \\
Unadjusted differences $^{++}$ & Reference & $157.9(-154.76,484.8)$ & $-90.5(-301.3,104.5)$ \\
Adjusted differences $^{+++}$ & Reference & $191.5(-62.5,506.3)$ & $-55.7(-250.0,143.6)$ \\
\hline
\end{tabular}

Note. ${ }^{+}$Intervention costs incurred by local authorities; ${ }^{++}$confidence intervals were calculated using 5000 non-parametric bootstrap replicates; ${ }^{+++}$The differences were adjusted for cost at baseline. Abbreviations. T1 Baseline, T2 Time 2 assessments 8-weeks post-baseline, T3 Time 3 assessments 52 -weeks post-baseline

diet, and obesity prevention research identified 48 eligible studies of which only $31 \%$ of studies reported a target sample size [Guagliano JM, Morton KL, Hughes C, van Sluijs EMF, unpublished data]. A subsequent survey showed that only $38 \%$ recruited their target sample size over a median (interquartile range) of 12 (7.5-52) weeks. Recruitment periods were extended in 33\% studies with a median extension of 20 (8-37.5) weeks [Guagliano JM, Morton KL, Hughes C, van Sluijs EMF, unpublished data]. In terms of recruitment, $94 \%$ of adults reported their ethnicity as white. While this figure is reflective of the population of the counties where recruitment occurred [57], the potential effectiveness of this intervention on minority families is unclear. Several studies have acknowledged the underrepresentation of minority groups in trials $[58,59]$. Therefore, further research is needed to better establish regarding how to recruit families in family-based research is needed, and in particular, greater consideration should be given to recruiting families of ethnic minority groups. Targeting specific recruitment settings or tailored messaging on recruitment materials are strategies that could be used [59, 60].

An extensive measurement protocol was applied in both the FRESH feasibility [19] and the current study, and it is not possible to disentangle whether the challenges of recruiting families were due to families having a lack of interest in increasing their physical activity, a lack of interest in FRESH in particular, or that the commitment to three rounds of home-based assessment of all family members was a barrier. Families in both the FRESH feasibility [19] and pilot studies indicated that the level of measurement was acceptable to them, but this is likely to be a biased perception of a group of families that has made the commitment to take part in the FRESH study. Further research is needed to identify whether families may not be interested in physical activity promotion per se, or whether the research commitment required poses a barrier. With this in mind, researchers and funders should carefully balance the scientific need for detailed data collection (driven for example by questions around how interventions work, and impacts on important physical health outcomes beyond the target behaviour) with the burden on participants and its impact on recruitment of a representative sample of participants.

Encouragingly, we found evidence of preliminary short-term effectiveness for adults and, in particular, for fathers in the FAM group. Similar interventions with mothers have resulted in positive physical activity promotion [61]. However, the effect on fathers may be noteworthy as evidence indicates that fathers have an independent influence on their children's health and development [62] and an important influence on children's physical activity [63-65].

Similar to other family-based physical activity interventions $[13,16,61]$, we did not find evidence of preliminary effectiveness for children or for co-participation in physical activity between parents and their children in this study. This may be due to a number of reasons. First, our process evaluation and focus groups revealed that family planning time was not being implemented as intended. In a family-based physical activity intervention that included a similar planning component, the authors found that children's MVPA significantly increased in the short-term compared to a condition that received education only [66]. Therefore, without implementing the planning component in our study, the step challenges alone may have not been enough to change children's MVPA. There were also group differences in children's sex and age, with fewer girls in the PED group and more older children in the FAM group. Observational data reveal that children's physical activity declines with age [8-10] and girls accumulate less physical activity than boys throughout childhood $[28,67]$, and girls' physical activity declines more precipitously than boys with age [68-70]. These differences may have affected preliminary intervention effectiveness on MVPA, but this issue would likely be resolved through randomisation in an adequately powered trial. Lastly, there may have a been a healthy volunteer bias as participants across groups were generally already meeting physical activity recommendations at baseline. In future, excluding families that are sufficiently active could be considered. 
Delivery of the FRESH intervention was estimated to cost $£ 90$ per family ( $£ 15$ per participant), including pedometers for all family members, face-to-face kick-off meeting and personalised follow-up support. The latter accounted for $\sim 55 \%$ of the costs. These costs could be reduced in future as this part of the intervention delivery had not been automated, but was processed manually by research staff. Further automation of these processes will help reduce delivery costs, and make it more attractive to funding agencies to consider delivering FRESH as part of their portfolio of physical activity interventions, if proven effective. Previous work has estimated the cost of delivering a multi-component school-based physical activity intervention at $\sim £ 190 /$ participant [71], and an after-school intervention at $£ 51 /$ participant [72], suggesting that cost of delivering the FRESH intervention is low in comparison. However, little is known about how much local authorities or other delivery agents are willing to pay, and future research should explore this.

\section{Strengths and limitations}

There are several noteworthy strengths of this study which include high retention rates, device-measured physical activity, a measure of family functioning, and a long-term follow-up assessment (i.e., 52-weeks postbaseline). There were also some limitations.

Despite bolstering our recruitment strategy after our feasibility study, we were still unable to recruit the desired number of families into this study; so further optimisation regarding recruitment in family-based research appears prudent. Also, the children and adults that participated in this pilot study were generally sufficiently physically active at baseline, which may have affected the potential of the intervention. Lastly, randomisation did not lead to balanced groups as there were large differences in sex and age among children across groups, where there were noticeably less girls in the PED group and older children in the FAM group. This may have affected our findings for preliminary intervention effectiveness. The randomisation procedure was likely affected by small sample size and the use of a stratified randomisation procedure by county due to funding. There is no indication that this issue would also affect an adequately powered trial; however, stratified randomisation by child sex and/or age could also be considered.

\section{Conclusion}

In conclusion, this study demonstrates feasibility and acceptability of the family-targeted FRESH intervention, as well as satisfying all progression criteria, at least partially. However, we failed to recruit the target sample size and did not find a signal of effectiveness on MVPA particularly long-term or in children. Therefore, further refinements around intervention delivery and recruitment may be required prior to progressing to a full-scale trial.

\section{Supplementary information}

Supplementary information accompanies this paper at https://doi.org/10. 1186/s12966-020-01025-3.

Additional file 1 Supplementary Table 1. Childrens' mean \pm standard deviation daily minutes in moderate-to-vigorous physical activity and sedentary time.

Additional file $\mathbf{2}$ Supplementary Table 2. Adults' mean \pm standard deviation daily minutes in moderate-to-vigorous physical activity and sedentary time.

Additional file $\mathbf{3}$ Supplementary Table 3. Mean daily minutes of family co-participation in light, moderate, and vigorous physical activity.

Additional file 4 Supplementary Table 4. Secondary outcomes for children.

Additional file $\mathbf{5}$ Supplementary Table $\mathbf{5}$. Secondary outcomes for adults.

Additional file 6 Supplementary Table 6 . Family functioning.

\section{Abbreviations}

FRESH: Families Reporting Every Step to Health; GPS: Global positioning system; MVPA: Moderate-to-vigorous physical activity

\section{Acknowledgements}

This work was undertaken by the Centre for Diet and Activity Research (CEDAR), where funding from Cancer Research UK, the British Heart Foundation, the Economic and Social Research Council, the Medical Research Council, the National Institute for Health Research, and the Wellcome Trust, under the auspices of the UK Clinical Research Collaboration, is gratefully acknowledged [087636/Z/08/Z; ES/G007462/1; $\mathrm{MR} / \mathrm{K} 023187 / 1]$.

\section{Authors' contributions}

EvS (principal investigator), $\mathrm{HEB}, \mathrm{CH}, \mathrm{APJ}$, and KLM secured funding for the research. All authors contributed to the study design. JMG drafted the manuscript. EC conducted family co-participation analyses, $\mathrm{CH}$ led family functioning analyses, FF conducted the economic analyses, and JMG conducted all other analyses. SA, HEB, EC, CH, APJ, FF, KLM, and EvS critically reviewed and revised the manuscript. All authors read and approved the final manuscript.

\section{Funding}

This work was supported by the National Institute for Health Research Public Health Research Programme (project number 15/01/19). Intervention costs for the current study were supported by Active Norfolk and Suffolk County Council. Funding was also received from the Medical Research Council (project number MC_UU_12015/7) and National Institute for Health Research Biomedical Research Centre Cambridge: Nutrition, Diet, and Lifestyle Research Theme (Grant IS-BRC-1215-20014). The views expressed are those of the author(s) and not necessarily those of the National Health Service, the National Institute for Health Research, or the Department of Health and Social Care.

\section{Availability of data and materials}

Data for research purposes are available upon request.

\section{Ethics approval and consent to participate}

All participants provided their written informed consent/assent. This study received ethical approval from the Ethics Committee for the School of the Humanities and Social Sciences at the University of Cambridge (ID number: 17/113).

Consent for publication

Not applicable.

Competing interests

The authors declare that they have no competing interest. 


\section{Author details}

MRC Epidemiology Unit and Centre for Diet and Activity Research, University of Cambridge, Cambridge, UK. ${ }^{2}$ Norwich Medical School and Centre for Diet and Activity Research, University of East Anglia, Norwich, UK. ${ }^{3}$ Department of Public Health and Primary Care, University of Cambridge, Cambridge, UK. ${ }^{4}$ Centre for Family Research, University of Cambridge, Cambridge, UK.

\section{Received: 15 July 2020 Accepted: 14 September 2020}

Published online: 22 September 2020

\section{References}

1. Ding D, Lawson KD, Kolbe-Alexander TL, Finkelstein EA, Katzmarzyk PT, van Mechelen W, Pratt M, Committee LPASE. The economic burden of physical inactivity: a global analysis of major non-communicable diseases. Lancet. 2016;388(10051):1311-24

2. Hallal PC, Andersen LB, Bull FC, Guthold R, Haskell W, Ekelund U. Global physical activity levels: surveillance progress, pitfalls, and prospects. Lancet. 2012;380(9838):247-57.

3. Health Survey for England 2016 physical activity in adults. 2016 [cited 2020 01.07]; Available from: http://healthsurvey.hscic.gov.uk/media/63730/HSE16Adult-phy-act.pdf

4. Bellows-Riecken $\mathrm{KH}$, Rhodes RE. A birth of inactivity? A review of physical activity and parenthood. Prev Med. 2008;46(2):99-110.

5. Condello G, Puggina A, Aleksovska K, Buck C, Burns C, Cardon G, Carlin A, Simon C, Ciarapica D, Coppinger T. Behavioral determinants of physical activity across the life course: a "DEterminants of Dlet and physical ACtivity"(DEDIPAC) umbrella systematic literature review. Int J Behav Nutr Phys Act. 2017;14:58

6. Corder K, Winpenny EM, Foubister C, Guagliano JM, Hartwig XM, Love R, Clifford Astbury C, van Sluijs EMF: Becoming a parent: a systematic review and meta-analysis of changes in BMl, diet and physical activity. 2019.

7. Griffiths LJ, Cortina-Borja M, Sera F, Pouliou T, Geraci M, Rich C, Cole TJ, Law C, Joshi H, Ness AR. How active are our children? Findings from the millennium cohort study. BMJ Open. 2013;3(8):e002893.

8. Brooke HL, Atkin AJ, Corder K, Ekelund U, van Sluijs EM. Changes in timesegment specific physical activity between ages 10 and 14 years: a longitudinal observational study. J Sci Med Sport. 2016;19(1):29-34.

9. Corder K, Craggs C, Jones AP, Ekelund U, Griffin SJ, van Sluijs EM. Predictors of change differ for moderate and vigorous intensity physical activity and for weekdays and weekends: a longitudinal analysis. Int J Behav Nutr Phys Act. 2013;10:69.

10. Corder K, Sharp S, Atkin AJ, Griffin S, Jones A, Ekelund U, van Sluijs E. Change in objectively measured physical activity during the transition to adolescence. Br J Sports Med. 2013;49(11):730-6.

11. Kaushal N, Rhodes RE. The home physical environment and its relationship with physical activity and sedentary behavior: a systematic review. Prev Med. 2014;67:221-37.

12. Maitland C, Stratton G, Foster S, Braham R, Rosenberg M. A place for play? The influence of the home physical environment on children's physical activity and sedentary behaviour. Int J Behav Nutr Phys Act. 2013;10(1):99.

13. O'Connor TM, Jago R, Baranowski T. Engaging parents to increase youth physical activity: a systematic review. Am J Prev Med. 2009;37(2):141-9.

14. van Sluijs EM, McMinn A. Preventing obesity in primary schoolchildren. BMJ. 2010;340:819

15. Kipping RR, Howe LD, Jago R, Campbell R, Wells S, Chittleborough CR, Mytton J, Noble SM, Peters TJ, Lawlor DA. Effect of intervention aimed at increasing physical activity, reducing sedentary behaviour, and increasing fruit and vegetable consumption in children: active for life year 5 (AFLY5) school based cluster randomised controlled trial. BMJ. 2014;348:348-61.

16. van Sluijs EM, Kriemler S, McMinn AM. The effect of community and family interventions on young people's physical activity levels: a review of reviews and updated systematic review. Br J Sports Med. 2011;45(11):914-22.

17. Rhodes RE, Lim C. Promoting parent and child physical activity together: elicitation of potential intervention targets and preferences. Health Educ Behav. 2018:45(1):112-23.

18. Shonkoff JP, Fisher PA. Rethinking evidence-based practice and twogeneration programs to create the future of early childhood policy. Dev Psychopathol 2013, 25(4 pt2):1635.

19. Guagliano JM, Brown HE, Coombes E, Hughes C, Jones AP, Morton KL, Wilson EC, van Sluijs EM. The development and feasibility of a randomised family-based physical activity promotion intervention: the families reporting every step to health (FRESH) study. Pilot Feas Stud. 2019;5:21.

20. Guagliano JM, Brown HL, Coombes E, Haines ES, Hughes C, Jones AP, Morton $\mathrm{KL}$, van Sluijs EM. Whole family-based physical activity promotion intervention: the families reporting every step to health pilot randomised controlled trial protocol. BMJ Open. 2019;9:e030902.

21. Guagliano JM, Brown HE, Coombes E, Hughes C, Jones AP, Morton KL, Wilson EC, van Sluijs EM. The development and feasibility of a randomised family-based physical activity promotion intervention: the families reporting every step to health (FRESH) study. Pilot Feas Stud. 2019;5(1):21.

22. Brown HE, Schiff A, van Sluijs EM. Engaging families in physical activity research: a family-based focus group study. BMC Public Health. 2015;15: 1178-86.

23. Stokols D. Translating social ecological theory into guidelines for community health promotion. Am J Health Promot. 1996;10(4):282-98.

24. Christensen P. The health-promoting family: a conceptual framework for future research. Soc Sci Med. 2004;59(2):377-87.

25. Deci EL, Ryan RM: Intrinsic motivation and self-determination in human behavior. Plenum, New York: Springer Science \& Business Media; 1985.

26. Choi L, Liu Z, Matthews CE, Buchowski MS. Validation of accelerometer wear and nonwear time classification algorithm. Med Sci Sports Exerc. 2011;43(2): 357-64.

27. Evenson KR, Catellier DJ, Gill K, Ondrak KS, McMurray RG. Calibration of two objective measures of physical activity for children. J Sports Sci. 2008;26(14): 1557-65.

28. Troiano RP, Berrigan D, Dodd KW, Mâsse LC, Tilert T, McDowell M. Physical activity in the United States measured by accelerometer. Med Sci Sports Exerc. 2008;40(1):181-8.

29. British National Grid. Beginners guide to grid references. 2020 [cited 2020 03.06]; Available from: https://getoutside.ordnancesurvey.co.uk/guides/ beginners-guide-to-grid-references.

30. Dunton GF, Liao Y, Almanza E, Jerrett M, Spruijt-Metz D, Pentz MA. Locations of joint physical activity in parent-child pairs based on accelerometer and GPS monitoring. Ann Behav Med. 2013;45(Suppl 1):S162-72.

31. Collings PJ, Wijndaele K, Corder K, Westgate K, Ridgway CL, Dunn V, Goodyer I, Ekelund U, Brage S. Levels and patterns of objectively-measured physical activity volume and intensity distribution in UK adolescents: the ROOTS study. Int J Behav Nutr Phys Act. 2014;11:23.

32. Pan H, Cole TJ: LMSgrowth program version 2.77. In. London, England: Child Growth Foundation; 2012.

33. Wareham NJ, Jakes RW, Rennie KL, Mitchell J, Hennings S, Day NE. Validity and repeatability of the EPIC-Norfolk physical activity questionnaire. Int J Epidemiol. 2002;31(1):168-74.

34. Corder K, van Sluijs EM, Wright A, Whincup P, Wareham NJ, Ekelund U. Is it possible to assess free-living physical activity and energy expenditure in young people by self-report? Am J Clin Nutr. 2009;89(3):862-70.

35. Lampard AM, Nishi A, Baskin ML, Carson TL, Davison KK. The activity support scale for multiple groups (ACTS-MG): child-reported physical activity parenting in African American and non-Hispanic White families. Behav Med. 2016:42(2):112-9.

36. van Sluijs EM, Skidmore PM, Mwanza K, Jones AP, Callaghan AM, Ekelund U, Harrison F, Harvey I, Panter J, Wareham NJ. Physical activity and dietary behaviour in a population-based sample of British 10-year old children: the SPEEDY study (sport, physical activity and eating behaviour: environmental determinants in Young people). BMC Public Health. 2008:8(1):388.

37. The EuroQol Group. EuroQol - a new facility for the measurement of healthrelated quality of life. Health Policy. 1990;16(3):199-208.

38. Brooks R. The EuroQol group: EuroQol: the current state of play. Health Policy. 1996:37(1):53-72.

39. Stevens KJ. Working with children to develop dimensions for a preferencebased, generic, pediatric, health-related quality-of-life measure. Qual Health Res. 2010;20(3):340-51.

40. Stevens KJ. Assessing the performance of a new generic measure of healthrelated quality of life for children and refining it for use in health state valuation. Appl Health Econ Health Policy. 2011;9(3):157-69.

41. Corder K, van Sluijs EM, McMinn AM, Ekelund U, Cassidy A, Griffin SJ. Perception versus reality: awareness of physical activity levels of British children. Am J Prev Med. 2010;38(1):1-8.

42. Godino JG, Watkinson C, Corder K, Sutton S, Griffin SJ, Van Sluijs EM. Awareness of physical activity in healthy middle-aged adults: a cross- 
sectional study of associations with sociodemographic, biological, behavioural, and psychological factors. BMC Public Health. 2014;14:421.

43. D'Haese S, Gheysen F, De Bourdeaudhuij I, Deforche B, Van Dyck D, Cardon G. The moderating effect of psychosocial factors in the relation between neighborhood walkability and children's physical activity. Int I Behav Nutr Phys Act. 2016;13(1):128.

44. Motl RW, Dishman RK, Trost SG, Saunders RP, Dowda M, Felton G, Ward DS, Pate RR Factorial validity and invariance of questionnaires measuring social-cognitive determinants of physical activity among adolescent girls. Prev Med. 2000;31(5):584-94.

45. Markland D, Tobin V. A modification to the behavioural regulation in exercise questionnaire to include an assessment of amotivation. J Sport Exerc Psychol. 2004;26(2):191-6.

46. Sebire SJ, Jago R, Fox KR, Edwards MJ, Thompson JL. Testing a selfdetermination theory model of children's physical activity motivation: a cross-sectional study. Int J Behav Nutr Phys Act. 2013;10:111.

47. Grotevant HD, Cooper CR. Patterns of interaction in family relationships and the development of identity exploration in adolescence. Child Dev. 1985; 56(2):415-28.

48. Bengston PL, Grotevant HD. The individuality and connectedness Q-sort: a measure for assessing individuality and connectedness in dyadic relationships. Pers Relat. 1999;6(2):213-25.

49. White IR, Thompson SG. Adjusting for partially missing baseline measurements in randomized trials. Stat Med. 2005;24(7):993-1007.

50. Drummond MF, Sculpher MJ, Claxton K, Stoddart GL, Torrance GW: Methods for the economic evaluation of health care programmes: Oxford university press; 2015.

51. Manca A, Hawkins N, Sculpher MJ. Estimating mean QALYs in trial-based cost-effectiveness analysis: the importance of controlling for baseline utility. Health Econ. 2005;14(5):487-96

52. Côté J, Salmela JH, Baria A, Russell S. Organizing and interpreting unstructured qualitative data. Sport Psychol. 1993;7:127-37.

53. Treweek S, Pitkethly M, Cook J, Fraser C, Mitchell E, Sullivan F, Jackson C, Taskila TK, Gardner H. Strategies to improve recruitment to randomised trials. Cochrane Database Syst Rev. 2018;2.

54. Planner C, Bower P, Donnelly A, Gillies K, Turner K, Young B. Trials need participants but not their feedback? A scoping review of published papers on the measurement of participant experience of taking part in clinical trials. Trials. 2019;20(1):381.

55. McDonald AM, Knight RC, Campbell MK, Entwistle VA, Grant AM, Cook JA, Elbourne DR, Francis D, Garcia J, Roberts I. What influences recruitment to randomised controlled trials? A review of trials funded by two UK funding agencies. Trials. 2006;7(1):9.

56. Morgan PJ, Jones RA, Collins CE, Hesketh KD, Young MD, Burrows TL, Magarey AM, Brown HL, Hinkley T, Perry RA. Practicalities and research considerations for conducting childhood obesity prevention interventions with families. Children. 2016;3(4):24-40.

57. Norfolk Insight. Data and information about Norfolk's population. 2020 [cited 2020 01.07]; Available from: http://www.norfolkinsight.org.uk/.

58. Robinson L, Adair P, Coffey M, Harris R, Burnside G. Identifying the participant characteristics that predict recruitment and retention of participants to randomised controlled trials involving children: aAsystematic review. Trials. 2016;17(1):294.

59. Cui Z, Seburg EM, Sherwood NE, Faith MS, Ward DS. Recruitment and retention in obesity prevention and treatment trials targeting minority or low-income children: a review of the clinical trials registration database. Trials. 2015;16(1):564

60. Schoeppe S, Oliver M, Badland HM, Burke M, Duncan MJ. Recruitment and retention of children in behavioral health risk factor studies: REACH strategies. Int J Behav Med. 2014;21(5):794-803.

61. Rhodes RE, Quinlan A. The family as a context for physical activity promotion. In: Group dynamics in exercise and sport psychology. Volume 2, edn. Edited by Beauchamp MR, Eys MA. Routledge; 2014. p. 203-21.

62. Sarkadi A, Kristiansson R, Oberklaid F, Bremberg S. Fathers' involvement and children's developmental outcomes: a systematic review of longitudinal studies. Acta Paediatr. 2008:97(2):153-8.

63. Lloyd AB, Lubans DR, Plotnikoff RC, Morgan PJ. Paternal lifestyle-related parenting practices mediate changes in children's dietary and physical activity behaviors: findings from the healthy dads, healthy kids community randomized controlled trial. J Phys Act Health. 2015;12(9):1327-35.
64. Lubans DR, Morgan PJ, Collins CE, Okely AD, Burrows T, Callister R. Mediators of weight loss in the Healthy dads, healthy Kids pilot study for overweight fathers. Int J Behav Nutr Phys Act. 2012;9:45-50.

65. Zahra J, Sebire SJ, Jago R. "He's probably more Mr. sport than me" - a qualitative exploration of mothers' perceptions of fathers' role in their children's physical activity. BMC Pediatr. 2015;15:101.

66. Rhodes RE, Blanchard CM, Quinlan A, Naylor P-J, Warburton DE. Family physical activity planning and child physical activity outcomes: a randomized trial. Am J Prev Med. 2019;57(2):135-44.

67. Hardy LL, Okely AD, Dobbins TA, Booth ML. Physical activity among adolescents in New South Wales (Australia): 1997 and 2004. Med Sci Sports Exerc. 2008;40(5):835-41.

68. Kimm SY, Glynn NW, Kriska AM, Barton BA, Kronsberg SS, Daniels SR Crawford PB, Sabry ZI, Liu K. Decline in physical activity in black girls and white girls during adolescence. N Engl J Med. 2002:347(10):709-15.

69. Nader PR, Bradley RH, Houts RM, McRitchie SL, O'Brien M. Moderate-tovigorous physical activity from ages 9 to 15 years. J Am Med Assoc. 2008; 300(3):295-305

70. Kahn JA, Huang B, Gillman MW, Field AE, Austin SB, Colditz GA, Frazier AL. Patterns and determinants of physical activity in US adolescents. J Adolesc Health. 2008;42(4):369-77.

71. Sutherland R, Reeves P, Campbell E, Lubans DR, Morgan PJ, Nathan N, Wolfenden L, Okely AD, Gillham K, Davies L, et al. Cost effectiveness of a multi-component school-based physical activity intervention targeting adolescents: the 'Physical activity 4 Everyone' cluster randomized trial. Int J Behav Nutr Phys Act. 2016:13:94.

72. Gc VS, Suhrcke M, Atkin AJ, van Sluijs E, Turner D. Cost-effectiveness of physical activity interventions in adolescents: model development and illustration using two exemplar interventions. BMJ Open. 2019;9(8):e027566.

\section{Publisher's Note}

Springer Nature remains neutral with regard to jurisdictional claims in published maps and institutional affiliations.
Ready to submit your research? Choose BMC and benefit from:

- fast, convenient online submission

- thorough peer review by experienced researchers in your field

- rapid publication on acceptance

- support for research data, including large and complex data types

- gold Open Access which fosters wider collaboration and increased citations

- maximum visibility for your research: over $100 \mathrm{M}$ website views per year

At $\mathrm{BMC}$, research is always in progress.

Learn more biomedcentral.com/submissions 